\title{
APOEع2 is associated with milder clinical and pathological Alzheimer's disease
}

\author{
Alberto Serrano-Pozo, MD, PhD ${ }^{1,2,6}$, Jing Qian, PhD $^{3}$, Sarah E. Monsell, $\mathbf{M S}^{5}$, Rebecca A. \\ Betensky, $\mathrm{PhD}^{2,4}$, and Bradley T. Hyman, MD, $\mathrm{PhD}^{1,2}$ \\ ${ }^{1}$ Department of Neurology, Massachusetts General Hospital, Boston, MA02116, USA \\ ${ }^{2}$ Massachusetts Alzheimer Disease Research Center, Charlestown, MA02129, USA \\ ${ }^{3}$ Division of Biostatistics and Epidemiology, University of Massachusetts, Amherst, MA01003, \\ USA \\ ${ }^{4}$ Department of Biostatistics, Harvard School of Public Health, Boston, MA02115, USA \\ ${ }^{5}$ National Alzheimer's Coordinating Center and Department of Epidemiology, University of \\ Washington, Seattle, WA98195, USA \\ ${ }^{6}$ Department of Neurology, University of lowa Hospitals \& Clinics, lowa city, IA52242, USA
}

\section{Abstract}

Objective-The Alzheimer disease (AD) APOE\&4 risk allele associates with an earlier age of onset and increased amyloid- $\beta$ deposition, whereas the protective APOE 2 allele delays the onset and appears to prevent amyloid- $\beta$ deposition. Yet the clinical and pathological effects of $A P O E \varepsilon 2$ remain uncertain because of its relative rarity. We investigated the effects of APOE $\varepsilon 2$ and $\varepsilon 4$ alleles on $\mathrm{AD}$ pathology and cognition in a large US dataset of well characterized AD patients.

Methods-We studied individuals from the National Alzheimer's Coordinating Center (NACC) autopsy cohort across the entire clinico-pathological continuum of AD. Multivariable models were built to examine the associations between $A P O E$ alleles and $\mathrm{AD}$ neuropathological changes, using the $A P O E \varepsilon 3 / \varepsilon 3$ group as comparator. Mediation analysis was used to estimate the direct and indirect effects of $A P O E$ alleles on AD pathology and cognition (CDR-SOB and MMSE).

Results-Compared to $A P O E \varepsilon 3 / \varepsilon 3, A P O E \varepsilon 2$ is independently associated with lower Braak NFT stages and, possibly, fewer neuritic plaques, but has no direct effect on CAA severity, whereas $A P O E \varepsilon 4$ is associated with more neuritic plaques and CAA, but has no independent effect on Braak NFT stage. Unadjusted analyses showed marked differences among APOE genotypes with respect to cognitive performance $(\varepsilon 2>\varepsilon 3>\varepsilon 4)$. Mediation analysis suggests that this is largely explained through effects on pathology.

Interpretation-Even when adjusted for age of onset, symptom duration and other demographic variables, $A P O E \varepsilon 2$ is associated with milder $\mathrm{AD}$ pathology and less severe antemortem cognitive

Correspondence and reprints to: Bradley T. Hyman, MD PhD. Massachusetts Alzheimer Disease Research Center. $16^{\text {th }}$ Street, Building 114, Charlestown, MA02129. bhyman @mgh.harvard.edu; Tel: 617-726-2299; Fax: 617-724-1480.

Conflict of Interest: The authors report no conflict of interest 
impairment compared to $A P O E \varepsilon 3$ and $\varepsilon 4$ alleles, suggesting a relative neuroprotective effect of APOE\&2 in $\mathrm{AD}$.

\section{Keywords}

Alzheimer disease; amyloid plaques; apolipoprotein E; cerebral amyloid angiopathy; neurofibrillary tangles

\section{Introduction}

The association of the apolipoprotein E (APOE) gene with sporadic Alzheimer disease (AD) is the strongest of any known risk gene. Compared with the major $\varepsilon 3$ allele, the APOE\&4 allele increases the risk of $\mathrm{AD}$ in a dose-dependent but not proportional fashion: carrying one copy of the $\varepsilon 4$ allele confers a 3-4 times increased life-risk of developing $\mathrm{AD}$, whereas carrying two copies increases this risk 8-12 times ${ }^{1-4}$. By contrast, compared to the major $A P O E \varepsilon 3$ allele, the $A P O E \varepsilon 2$ allele reduces the risk of developing AD by almost half ${ }^{5-9}$.

A number of postmortem quantitative studies have established that the APOE\&4 allele correlates with increased amyloid plaque deposition in the brain ${ }^{3,10-20}$ and with increased vascular amyloid deposition in the form of cerebral amyloid angiopathy (CAA) $)^{10,20-26}$. These findings have been more recently corroborated by in vivo amyloid PET imaging not only in $\mathrm{AD}$ patients, but also in cognitively intact elderly people ${ }^{27-31}$. While $A P O E \varepsilon 3 / \varepsilon 3$ carriers can still develop $\mathrm{AD}$, taken together, this evidence emphasizes the role of APOEE4 as an initiator of the amyloid cascade that ultimately leads to fully established $\mathrm{AD}^{32,33}$. Conversely, although some postmortem studies ${ }^{14,16,17,19,34}$ have ascribed increased numbers of neurofibrillary tangles (NFTs) - the other pathological hallmark of the disease — to the APOE\&4 allele, others have not found such association ${ }^{11,20}$, including those controlling for plaque burden in multivariable models ${ }^{35,36}$.

In contrast to $A P O E \varepsilon 4$ carriers, $A P O E \varepsilon 2$ carriers are thought to bear fewer amyloid plaques $^{14,17,19,34,37,38}$ and possibly also fewer NFTs ${ }^{14,34}$. However, in part because of the relative rarity of this allele, sufficiently powered and detailed postmortem studies examining the effects of the APOE\&2 allele on the pathobiology of $\mathrm{AD}$ are still lacking.

We examined the association between the APOE alleles and the AD pathological hallmarks and cognitive outcomes using the National Alzheimer's Coordinating Center (NACC) autopsy cohort, a large multicenter longitudinal cohort study of aging involving the 34 past and present National Institute on Aging-funded Alzheimer Disease Centers (NIA-funded ADCs) across the United States. We hypothesized that the large size of this multi-center intensively studied cohort would enable us to find novel pathophysiological relationships that may have remained undetectable in prior studies due to lack of statistical power. Because concurrent Lewy bodies and cerebrovascular pathologies have been reported to contribute to cognitive impairment in prior population-based clinico-pathological studies, in order to examine the impact of $A P O E$ alleles on AD-related pathological and cognitive outcomes, we selected individuals with no primary neuropathological diagnosis other than AD neuropathological changes. Specifically, we aimed to evaluate the effects of the $\varepsilon 2$ and $\varepsilon 4$ alleles on the main pathological hallmarks of $\mathrm{AD}$ [neuritic plaques, neurofibrillary 
tangles (NFTs), and cerebral amyloid angiopathy (CAA)]; and assess if there is a direct or indirect effect of these $A P O E$ alleles on the severity of cognitive impairment using mediation analysis.

\section{Subjects \& Methods}

\section{Inclusion and exclusion criteria}

Subjects were participants in a longitudinal cohort study of aging in any of the past and present 34 NIA-funded ADCs. This multicenter study has been described in detail elsewhere ${ }^{39-41}$. Briefly, subjects undergo a baseline visit and annual follow-up visits in which a Uniform Data Set (UDS) is completed, including a minimum subject demographics data set, and standard motor, behavioral, functional, and neuropsychological assessments. Subjects were eligible for this study if they met the following inclusion criteria: 1) no primary neuropathological diagnosis other than AD neuropathological changes was found at autopsy; 2) final clinical evaluation within 2 years of death; 3) age of death 50 years old or older; and 4) $A P O E$ genotype available. Exclusion criteria were aimed at minimizing statistical noise in genotype-phenotype correlations and included: 1) a primary neuropathological diagnosis other than AD neuropathological changes (i.e., frontotemporal lobar degeneration, dementia with Lewy bodies, hippocampal sclerosis, vascular dementia, prion disease, Parkinson disease, Huntington disease, hypoxia, ischemia, necrosis, hemorrhage, other non-neurodegenerative diagnosis); 2) cognitive impairment attributable to alcohol use, depression, medication use, or medical illness; 3) carrying an $A P O E \varepsilon 2 / \varepsilon 4$ genotype (since we aimed at investigating the separate effects of $A P O E \varepsilon 2$ and $A P O E \varepsilon 4$ on $\mathrm{AD}$ pathological lesions and cognitive outcomes), and 4) being cognitively intact (CDR$\mathrm{SOB}=0$ ) at last clinical evaluation (in order to prevent artificially significant results due to the "anchoring" effect of cognitively intact subjects, who typically have low levels of AD pathology and are less likely to carry the APOEE4 allele).

\section{Data collection}

Demographic and clinical data used in this study included sex, years of education, age of death, age of onset, symptom duration (age of death - age of onset), APOE genotype, last clinical dementia rating sum of boxes $(\mathrm{CDR}-\mathrm{SOB})^{42}$ score, and last Mini Mental State Examination (MMSE) ${ }^{43}$ score. The education level was categorized in 4-year intervals roughly corresponding to the education stages of high school, undergraduate college, and post-college education. Since we excluded subjects with $\mathrm{CDR}-\mathrm{SOB}=0$, values of CDR-SOB in this study range from 0.5 to 18 , with higher values indicating worse cognitive/functional status. Supplemental tables 1 and 2 provide information about cognitively intact (CDR$\mathrm{SOB}=0$ ) subjects for comparison purposes.

Neuropathological variables included the Braak stage of NFTs (0: none; I-II: entorhinal; IIIIV: limbic, and V-VI: isocortical) ${ }^{44,45}$, the CERAD score of neuritic plaques (none/sparse, moderate, or frequent $)^{46}$, the presence of incidental Lewy bodies in any region, and the extent of vascular pathology (CAA, small and large vessel disease, and hippocampal sclerosis). Although the Thal phases of amyloid deposition ${ }^{47}$ have been recently implemented in NACC neuropathological assessment, they were not available for most 
subjects in this study, therefore we could not use the $\mathrm{ABC}$ score of $\mathrm{AD}$ neuropathological changes ${ }^{48,49}$ for clinico-pathologic correlations. While more objective and quantitative methods of assessment are under development, NACC neuropathology guidelines recommend the use of a qualitative and subjective grading system of the overall severity (rather than an individual vessel) to assess arteriosclerosis, atherosclerosis, and CAA (none, mild, moderate, or severe). Arteriosclerosis refers to the hyalinosis of the media and adventitia (arteriolosclerosis) of small parenchymal and/or leptomeningeal vessels, whereas atherosclerosis refers to the presence of intimal and medial fibro-fatty atheromatous plaques in large arteries at the base of the brain (i.e., circle of Willis). Hippocampal sclerosis was defined as the presence of selective neuronal loss and gliosis ("sclerosis") limited to CA1 and subiculum, with variable additional involvement of endplate, CA2, entorhinal cortex, and amygdala.

\section{Statistical analyses}

The association of the presence of $A P O E$ alleles with ordered categories of AD pathological hallmarks (neuritic plaques, NFTs, or CAA) in the cognitively impaired (CDR-SOB $>0$ ) group was examined with adjacent-categories logit model ${ }^{50}$, which allow a covariate to have a constant effect across some or all categories, using the "VGAM" package in R software $^{51}$. This flexibility of the adjacent-categories logit model enabled us to fit a parsimonious regression model for ordered categories of AD pathological hallmarks without strong parametric assumptions on the relationship among ordered categories. For each covariate, the assumption that it has the same effect for each category was checked using likelihood ratio tests of nested models. Whenever the assumption was violated, nested sequences of weaker assumptions permitting separate effects of a covariate for some logits were considered and were checked using likelihood ratio tests, until the most parsimonious assumption allowing different effects for different logits was not rejected. We have previously used this approach to examine the correlations between neuropathology and cognition (CDR-SOB) across the AD continuum ${ }^{52}$.

To assess the possible pathobiological pathways linking $A P O E$ alleles with AD pathological hallmarks and whether there is a direct effect of each of these alleles on cognitive performance and/or an indirect effect through any of the AD pathological hallmarks, mediation analysis was conducted using the counterfactual framework ${ }^{53}$. To adjust for multiple mediators simultaneously, the methods proposed by Imai and Yamamoto ${ }^{54}$ were adopted. Because neuritic plaques and NFTs from different APOE genotypes are biochemically and immunohistochemically similar, we assumed that no interaction exists between $A P O E$ genotype and the AD pathological hallmarks with respect to cognitive performance; in other words, that the effect of the pathological mediators on cognition does not differ across $A P O E$ genotypes for a given severity score or stage of pathology (i.e., Braak NFT stage VI). We made this same assumption of no interaction between APOE genotype and each $\mathrm{AD}$ pathological hallmark with respect to the other pathological hallmarks. The "mediation" package in R software ${ }^{55}$ was used to perform the mediation analysis with multiple mediators. The estimation algorithms involve fitting varying coefficient linear structural equations models: one model has the outcome of interest (e.g., $\mathrm{CDR}-\mathrm{SOB}$ ) as the dependent variable and the indicator of $A P O E$ allele, the multiple 
mediators, and the confounders as covariates whereas, for each mediator, there is another model having this mediator variable (e.g., Braak NFT stage) as the dependent variable and the indicator of $A P O E$ allele, the confounders, and all the other mediators as covariates. A Monte Carlo simulation-based method is then used to estimate the average direct and indirect effects ${ }^{53}$. Because the mediation analysis software that is available does not handle ordinal outcome data, which includes CERAD neuritic plaque scores, Braak NFT stages, extent of CAA, CDR-SOB and MMSE, we treated them as continuous measures. This artificially inflated the power of these analyses (Tables 4 and 5), as it assumes a linear relationship among the ordinal categories of the variables; however, it is likely not problematic for the cognitive outcomes, as they have many ordinal categories that may behave piecewise linearly. For this reason, and because mediation analyses were our primary interest, we did not undertake the ordinal regression analysis for CDR-SOB or MMSE. We treated plaques and NFTs as binary mediator variables in the CDR-SOB and MMSE analyses (cutoff values are presented in footnote of Table 4). In addition, the mediation analyses for the $A P O E$ alleles $\varepsilon 2$ and $\varepsilon 4$ were conducted separately, that is, subjects with the $\varepsilon 4$ allele were excluded from the $\varepsilon 2$ allele mediation analysis, and vice versa.

In this study we did not adjust for potential selection bias associated with the decision to undergo autopsy as we found similar results with and without this adjustment, performed with inverse probability weighting, in our prior study on the NACC autopsy cohort ${ }^{52}$.

\section{Results}

\section{Description of the sample}

The flow-chart in Figure 1 depicts the selection procedure and the number of subjects excluded by each exclusion criterion. As of March 2014, the 2005-2014 NACC autopsy cohort consisted of 2987 subjects, of whom 793 subjects met all the eligibility criteria and did not meet any of the exclusion criteria. The distribution of $A P O E$ genotypes in this final sample was the following: $\varepsilon 2 / \varepsilon 2=1$ (0.1\%), $\varepsilon 2 / \varepsilon 3=40$ (5.0\%), $\varepsilon 3 / \varepsilon 3=339$ (42.7\%), $\varepsilon 3 / \varepsilon 4=320$ $(40.3 \%)$, and $\varepsilon 4 / \varepsilon 4=93(11.7 \%)$. Allelic frequencies in this AD enriched autopsy cohort were distributed as follows: $\varepsilon 2=2.6 \%, \varepsilon 3=65.4 \%$, and $\varepsilon 4=31.9 \%$.

Table 1 shows the demographic characteristics of the study subjects by $A P O E$ genotype. For the purpose of comparison, Supplemental Table 1 describes the subjects with $\mathrm{CDR}-\mathrm{SOB}=0$ who were excluded from the study. Sex and education were not significantly different across genotypes, but there were major differences in AD-related clinical phenotypes across the different genotypes. Besides the well-established association between genotype and age of symptom onset and death $(\varepsilon 4<\varepsilon 3<\varepsilon 2)$, these unadjusted analyses also revealed a strong correlation between genotype and antemortem degree of cognitive impairment $(\varepsilon 4>\varepsilon 3>\varepsilon 2)$. The latter differences were striking despite excluding cognitively intact subjects (CDR$\mathrm{SOB}=0$ ): the average MMSE score of $A P O E \varepsilon 2$ carriers was 20.5, whereas the average MMSE score of $A P O E \& 4$ carriers was only 11.9 for one copy and 9.7 for two copies of the allele. 
Table 2 depicts the scores of each AD pathological hallmark as recorded within the NACC database (CERAD score of neuritic plaques, Braak NFT stage, and CAA severity) by APOE genotype. Hippocampal sclerosis, arteriosclerosis, atherosclerosis, and Lewy bodies are also presented. The subjects with $\mathrm{CDR}-\mathrm{SOB}=0$ excluded from the analyses below are described in Supplemental Table 2 for the purpose of comparison. Major differences between genotypes can be observed in the summary data of Table 2: among APOE\&2 carriers with impaired cognition at death, just fewer than half (18 out of $41, \sim 44 \%$ ) had sparse or no neuritic plaques whereas this number is almost 10-fold lower for APOE\&4 carriers (21 out of 413, $\sim 5 \%$ ). Similarly, only 27\% of APOE 2 carriers (11 out of 41) were Braak V/VI, the most severe NFT stages, whereas almost $90 \%$ of APOEE4/4 carriers (81 out of 93) had this widespread distribution of NFTs. Last, moderate or severe CAA was present in only $\sim 27 \%$ of APOE\&2 carriers ( 10 out of 41 ), as opposed to $~ 72 \%$ of $A P O E \varepsilon 4 / \varepsilon 4$ carriers (67 out of 93).

Next we examined the complex relationships between $A P O E$ alleles, AD neuropathology, and cognitive performance prior to death.

\section{Effects of APOE alleles on AD pathological hallmarks}

To investigate the independent effects of the APOEE2 and the APOE\&4 alleles on the presence and severity of each of these AD pathological hallmarks, we constructed multivariable models including all three pathological lesions and all demographic and clinical variables (age of death, sex, education, and symptom duration), using the $A P O E \varepsilon 3 / \varepsilon 3$ group as reference group (Table 3 ). While individuals with a primary neuropathological diagnosis of Lewy body disease, hippocampal sclerosis, and cerebrovascular disease were excluded from the study, the "incidental" finding of these lesions was allowed. However, univariate analyses in this group of cognitively impaired (CDR-SOB $>0$ ) individuals revealed no correlation of Lewy bodies, hippocampal sclerosis, arteriosclerosis (parenchymal small vessel disease), or atherosclerosis of large arteries with carrying either of the $A P O E$ alleles. Therefore these neuropathological variables were not included in the multivariable models.

Effect of APOE $\varepsilon 2$ and $\varepsilon 4$ alleles on neuritic plaques-After controlling for age of death, sex, education, symptom duration, Braak stage of NFTs, and severity of CAA, there was a significant positive association between the presence of the APOE\&4 allele and the density of neuritic plaques as assessed with CERAD scores compared to the APOEE3/\&3 genotype, with a higher density in $A P O E \varepsilon 4$ carriers. By contrast, compared to the $A P O E \varepsilon 3 / \varepsilon 3$ group, the presence of the $A P O E \varepsilon 2$ allele was not significantly associated with a lower density of neuritic plaques (although see further analysis and discussion below).

Effect of APOE $\varepsilon 2$ and $\varepsilon 4$ alleles on cerebral amyloid angiopathy-Similarly, after controlling for age of death, sex, education, symptom duration, Braak stage of NFTs, and CERAD score of neuritic plaques, there was a significant positive association between the presence of the $A P O E \varepsilon 4$ allele and the risk of CAA, with a higher risk of having mild versus none CAA and moderate versus mild CAA, but not severe versus moderate CAA, in $A P O E \varepsilon 4$ carriers compared to the $A P O E \varepsilon 3 / \varepsilon 3$ group. Split analyses by number of APOE\&4 
alleles revealed a clear dose-dependent association. Carrying one APOE\&4 allele was associated with a higher risk of mild but not moderate or severe CAA, whereas carrying two $A P O E \varepsilon 4$ alleles was associated with a higher risk of having moderate and severe but not mild CAA. By contrast, compared to the $A P O E \varepsilon 3 / \varepsilon 3$ genotype, there was no significant association between the presence of the $A P O E \varepsilon 2$ allele and the risk of CAA.

Effect of APOE $\varepsilon 2$ and $\varepsilon 4$ alleles on neurofibrillary tangles-Neither the presence of the $A P O E \varepsilon 4$ allele nor the number of $A P O E \varepsilon 4$ alleles was significantly associated with a higher risk of having more advanced Braak stages than the $A P O E \varepsilon 3 / \varepsilon 3$ group, when controlling for age of death, sex, education, symptom duration, CERAD score of neuritic plaques, and CAA severity. By contrast, carrying an APOEE2 allele was significantly associated with a lower risk of having a higher Braak stage of NFTs, compared to the $A P O E \varepsilon 3 / \varepsilon 3$ genotype.

\section{Pathobiological pathways linking APOE alleles with AD pathological hallmarks}

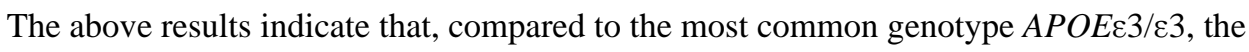
$A P O E \varepsilon 2$ allele is independently associated with a lower Braak NFT stage, whereas the $A P O E \varepsilon 4$ allele is independently associated with both a higher density of neuritic plaques and a higher severity of CAA. To investigate possible pathobiological pathways leading from these $A P O E$ alleles to their pathological correlates, we performed separate mediation analyses with each of the three AD pathological hallmarks as outcome variables, and the other two as mediators (Table 4). All analyses were adjusted by age of death, sex, and education, and $A P O E \varepsilon 4$ analyses were also adjusted by symptom duration, presence of hippocampal sclerosis, and severity of arteriosclerosis (ischemic small vessel disease). The $A P O E \varepsilon 2$ analyses could not adjust for these additional variables due to the small sample size.

These mediation analyses revealed that the protective effect of the APOE\&2 allele against NFTs can be explained by two mechanisms: a direct effect of the APOE\&2 allele and an indirect pathway mediated through its effect on neuritic plaques, both with similar magnitude. Of note, these analyses also suggested a protective effect of the APOE\&2 allele against neuritic plaques resulting from two effects of similar size: a direct effect against neuritic plaques and an indirect consequence of its protective effect on NFTs. Mediation analyses also revealed that the $A P O E \varepsilon 2$ allele has no significant direct effect on CAA severity but does have a significant indirect protective effect mediated through its lowering of both neuritic plaques and NFTs.

The accumulation of neuritic plaques associated with the APOEE 4 allele is the result of a direct effect and, to a lesser extent, of an indirect pathway involving its effect on NFTs, but not on CAA. Similarly, the increasing severity of CAA associated with the APOEE4 allele stems mainly from a direct effect, although its effects on neuritic plaques and NFTs also contribute to some extent. Last, the APOEE4 allele has no direct effect on NFTs, but may promote NFTs formation and/or spreading by indirect pathways involving its significant enhancing effects on neuritic plaques and, to a lesser extent, CAA. 


\section{Lack of independent effect of APOE $\varepsilon 2$ and $\varepsilon 4$ alleles on cognition}

We have recently reported in this same autopsy cohort that the extent of neuritic plaques (as measured by CERAD scores) and NFTs (as measured by Braak stage), severe CAA, severe parenchymal small vessel disease, and the presence of hippocampal sclerosis, all independently predict a higher degree of antemortem cognitive impairment as measured by CDR-SOB, whereas education level is an independent protective factor against cognitive impairment ${ }^{52}$. Herein, we examined whether the APOE genotype impacts cognition independently of both demographics and neuropathology. Specifically, we tested the hypothesis that possessing the $A P O E \varepsilon 2$ allele directly or indirectly protects against cognitive deficits, whereas carrying the $A P O E \varepsilon 4$ allele directly or indirectly contributes to cognitive impairment, as captured by CDR-SOB score or MMSE score prior to death. To distinguish between an effect mediated by neuropathological variables (indirect) or an independent (direct) effect of each allele, mediation analyses were carried out controlling for all the demographic/clinical (age of death, sex, education, age of onset, and symptom duration) and neuropathological characteristics. Although the total effect of APOEE2 on CAA was nonsignificant (Table 4), the effect was not negligible (0.14) and the confidence interval was wide and non-symmetric $(-0.53,0.26)$. For these reasons, in spite of the non-significance, we considered it as a mediator of $A P O E \varepsilon 2$ in the CDR-SOB model. Because the APOEE2 and $\varepsilon 4$ alleles are known to have opposite effects on age of onset of cognitive decline - APOE\&2 delays onset whereas $A P O E \varepsilon 4$ anticipates it-, we also tested age of onset as a mediator of indirect effects of $A P O E$ alleles on cognition.

Neither the $A P O E \varepsilon 2$ allele nor the $A P O E \varepsilon 4$ allele had a significant independent (direct) impact on cognition as measured with CDR-SOB and as compared to the more common genotype APOE $3 / \varepsilon 3$ (Table 5). Similar results were observed using the MMSE score as the cognitive outcome. However, the APOEE2 allele did exert an indirect protective effect against cognitive impairment that was mediated through its lowering effect on NFTs and, to a lesser extent, through its lowering effect on neuritic plaques. CAA could not be tested as a mediator of $A P O E \varepsilon 2$ allele-induced cognitive effects due to instability of the model. The protective effect on antemortem cognition associated with the APOEE2 allele was not mediated by the delayed age of onset also associated with this allele. Conversely, the $A P O E \varepsilon 4$ allele had an indirect deleterious effect on cognition mediated by all three $\mathrm{AD}$ neuropathological lesions. In addition, the effect of $A P O E \varepsilon 4$ on the age of onset of cognitive decline significantly contributed to the severity of cognitive impairment prior to death, even after controlling for symptom duration.

\section{Discussion}

The examination of raw data and unadjusted statistical analyses describing this large cognitively impaired autopsy cohort (Tables 1 and 2) suggested that, compared to the most common $A P O E \varepsilon 3 / \varepsilon 3$, carrying the $A P O E \varepsilon 4$ allele may be associated with both a more severe clinical expression (i.e., younger age of onset and poorer cognition prior to death) and a more advanced pathological phenotype (i.e., higher scores for neuritic plaques and CAA) of $\mathrm{AD}$, whereas carrying the $A P O E \varepsilon 2$ allele may imply developing a clinically and pathologically milder form. This would be in agreement with the known opposite effects of 
these $A P O E$ alleles on the risk of developing AD. However, the relationships between genotype and phenotype can be so complex that robust statistical methods and multivariable analyses are necessary to account for confounding and mediator factors. The results of these analyses support the above interpretation and can be summarized as follows: 1) Compared to $A P O E \varepsilon 3 / \varepsilon 3, A P O E \varepsilon 2$ is independently associated with both lower Braak stages of NFTs and fewer neuritic plaques, but has no independent effect on CAA severity; 2) compared to $A P O E \varepsilon 3 / \varepsilon 3, A P O E \varepsilon 4$ is associated with higher numbers of neuritic plaques and higher severity of CAA, but has no independent effect on NFTs; 3 ) besides these direct effects of $A P O E \varepsilon 2$ and $\varepsilon 4$ alleles on each $\mathrm{AD}$ lesion, additional indirect effects mediated through the other two AD pathological hallmarks were identified; 4) neither APOE\&2 nor APOE\&4 has an independent impact on cognition prior to death, but each indirectly affects cognition through its effects on $\mathrm{AD}$ neuropathological changes.

The main novel finding of this study is a significant negative direct effect of the APOEE2 allele on the Braak stage of NFT, suggesting a protective effect of the apolipoprotein E2 against NFT formation and spreading, whereas APOEE4 does not exhibit the opposite effect. Mediation analyses indicated that two effects equally contributed to this negative association between $A P O E \varepsilon 2$ and NFTs: a direct effect of APOE\&2 and an indirect mechanism through its plaque-lowering effect. Several proposed pathophysiological mechanisms could underlie these findings. First, apolipoprotein $\mathrm{E}$ (apoE) may directly interact with tau protein, the main constituent of NFTs, and apoE2 may interact with tau to a different extent than the other apoE isoforms ${ }^{56-60}$. Second, APOE 2 may indirectly contribute to restrict NFT spreading to cortical areas and determine a lower Braak stage by protecting against the accumulation of soluble $A \beta$ oligomeric species — probably not well captured by the CERAD neuritic plaque score - and plaques ${ }^{61}$ and by protecting against synaptotoxicity and neurotoxicity of existing plaques downstream $A \beta$ accumulation ${ }^{61,62}$. By contrast, the association of $A P O E \varepsilon 4$ allele and Braak stage of NFT was not significant after controlling for plaques and CAA, arguing against a significant direct effect of the APOEE4 allele on NFT formation and spreading. Indeed, in agreement with prior work ${ }^{36,63}$, our mediation analyses suggested that the positive association between the APOEE4 allele and the Braak NFT stage was largely explained by the $A P O E \varepsilon 4$ allele effect on plaques.

The mediation analys also demonstrate that the augmentation of neuritic plaques and CAA induced by the APOE\&4 allele was primarily a direct effect, supporting its role as initiator of amyloid deposition both at the brain parenchyma and at the blood vessel wall in the form of CAA. This result is in agreement with numerous postmortem quantitative and amyloid PET studies that have established that the increased risk of AD induced by APOE\& 4 is associated with a higher amyloid burden. Recent experimental data indicate that the apoE4 increases the amount of synaptotoxic soluble $A \beta$ oligomeric species ${ }^{61,64,65}$ and impairs $A \beta$ clearance $^{61,66}$.

While the ordinal regression model in Table 3 detected a protective effect of the APOEE2 allele against neuritic plaques when compared to the $A P O E \varepsilon 3 / \varepsilon 3$, this association was not found to be statistically significant likely due to lack of power, as suggested by the upper limit of the $95 \%$ confidence interval for the log odds ratio just above zero. Mediation analyses did yield a statistically significant result, although this statistical significance was 
likely contributed by the greater power afforded by the mediation analysis due to its modeling of CERAD neuritic plaque score as continuous, rather than ordinal. In addition, due to the small sample size, the APOE\&2 mediation analysis was not able to control for symptom duration, which may be a confounder also contributing to this statistical significance given its significant association with a higher Braak stage $(p<0.0001)$ and marginally significant association with a higher CERAD score $(p=0.07)$ in the ordinal regression models. In any case, the protective effect of the $A P O E \varepsilon 2$ allele against neuritic plaques was equally explained by a direct effect on plaques and an indirect mechanism, mediated through its NFT-lowering effect. This latter indirect effect appears to imply a synergistic interaction between tangles and plaques that has been postulated based on experimental data ${ }^{67,68}$.

Although significant indirect protective effects of the APOE\&2 allele on CAA severity were detected by mediation analysis, the total and direct effects were not significant, and the association between $A P O E \varepsilon 2$ allele and CAA severity was not significant in the ordinal regression model. This neutral total effect of the APOEE2 allele on the extent of CAA is consistent with prior work suggesting that the $A P O E \varepsilon 2$ allele is not associated with a higher incidence of vascular amyloid deposition ${ }^{26,69}$. The current NACC autopsy data set did not allow us to confirm the previously described association between the APOEE2 allele and a higher incidence of vasculopathic changes in amyloid- $\beta$-laden vessels leading to a higher risk of CAA-related hemorrhages.

Whether the APOE genotype independently and directly influences the rate of cognitive decline in $\mathrm{AD}$ has been a matter of controversy. Multiple clinical studies have attributed to the $A P O E \varepsilon 4$ allele either an accelerating, a neutral ${ }^{70-77}$, or even a slowing effect $^{78-80}$ on the rate of cognitive decline once $\mathrm{AD}$ has been diagnosed. By contrast, compared to the $A P O E \varepsilon 3 / \varepsilon 3$ genotype, the APOE\&2 allele has been associated with a reduced decline ${ }^{81,82}$. However, all these clinical studies lacked autopsy confirmation and, therefore, were not able to study the effect of the APOE genotype on cognition in the context of the neuropathological lesions. This is of critical importance because up to $30 \%$ of subjects diagnosed with probable AD in US NIA-funded ADCs have other neuropathological diagnoses causing or contributing to their cognitive deficits, or insufficient $\mathrm{AD}$ neuropathological changes at autopsy to fulfill current AD neuropathological diagnostic criteria $^{83,49,48,84}$. In this study $A P O E \varepsilon 2$ predicted substantially less severe cognitive impairment at the time of death, whereas APOEE4 was associated with a more severe cognitive impairment. However, these effects were seemingly entirely mediated by the impact of both alleles on AD neuropathological changes. Indeed, we observed no significant direct effect (i.e., independent of pathological lesions) of either of the APOE alleles on the CDR-SOB or MMSE score prior to death. We did, however, observe significant indirect effects of both $A P O E$ alleles on cognition mediated by their opposite effects with respect to the accumulation of $\mathrm{AD}$ neuropathological lesions. In addition, part of the detrimental effect of the $A P O E \varepsilon 4$ allele on antemortem cognition was mediated by its effect on the age of onset of cognitive decline. The $A P O E \varepsilon 4$ allele is known to anticipate the onset of cognitive decline in $\mathrm{AD}$, and $A P O E \varepsilon 4$ carriers exhibited a more severe cognitive impairment prior to death the younger they were at clinical onset, even after controlling for symptom duration. 
In order to prevent "false" statistically significant results derived from an overrepresentation of the $A P O E \varepsilon 2$ allele and an under representation of the APOE\&4 allele among the cognitively intact subjects, we decided to exclude subjects with $\mathrm{CDR}-\mathrm{SOB}=0$ and focused our statistical analyses in the continuum of cognitive decline ranging from subjective cognitive complaints and mild cognitive impairment (CDR-SOB=0.5-3.0) to end-stage dementia $(\mathrm{CDR}-\mathrm{SOB}=18)$. While this conservative design reinforces the validity of the statistically significant results obtained, the power to detect other statistically significant and clinically relevant associations may have been hampered by a smaller sample size, particularly for the APOE\& 2 allele group $(\mathrm{n}=41)$ and for the detection of early direct or indirect effects of $A P O E$ alleles on cognition.

In summary, the analysis of this large autopsy sample of cognitively impaired elderly subjects selected to examine the clinico-pathological continuum of Alzheimer disease with regression and mediation models led us to the novel finding that the APOE\&2 allele is independently associated with a lower Braak NFT stage. This observation implies a protective effect of the $A P O E \varepsilon 2$ allele against spreading of neurofibrillary tangle pathology to the neocortex and warrants future experimental studies modeling the interaction between apolipoprotein $\mathrm{E}$ and tau. We also confirmed the association of the APOE\&4 allele with a higher density of neuritic plaques and a more severe degree of CAA. These data also emphasize the impact of the $A P O E$ genotype in the clinical presentation and course of AD, with the major impact of the $A P O E \varepsilon 4$ allele on amyloid variables and a surprisingly strong impact of $A P O E \varepsilon 2$ on the spread of NFTs to the cortex leading to clinically meaningful differences in severity of dementia at death. Thus, $A P O E \varepsilon 2$ appears to lead to a milder form of $\mathrm{AD}$.

\section{Supplementary Material}

Refer to Web version on PubMed Central for supplementary material.

\section{Acknowledgments}

This work was supported by the Massachusetts Alzheimer's Research Center (NIH grant P50 AG0001534 to BTH). The NACC database is funded by the NIH National Institute on Aging grant U01 AG016976.

\section{References}

1. Corder EH, Saunders AM, Strittmatter WJ, et al. Gene dose of apolipoprotein E type 4 allele and the risk of Alzheimer's disease in late onset families. Science. 1993; 261(5123):921-923. [PubMed: 8346443]

2. Poirier J, Davignon J, Bouthillier D, et al. Apolipoprotein E polymorphism and Alzheimer's disease. Lancet. 1993; 342(8873):697-699. [PubMed: 8103819]

3. Rebeck GW, Reiter JS, Strickland DK, Hyman BT. Apolipoprotein E in sporadic Alzheimer's disease: allelic variation and receptor interactions. Neuron. 1993; 11(4):575-580. [PubMed: 8398148]

4. Saunders AM, Strittmatter WJ, Schmechel D, et al. Association of apolipoprotein E allele epsilon 4 with late-onset familial and sporadic Alzheimer's disease. Neurology. 1993; 43(8):1467-1472. [PubMed: 8350998]

5. Benjamin R, Leake A, McArthur FK, et al. Protective effect of apoE epsilon 2 in Alzheimer's disease. Lancet. 1994; 344(8920):473. [PubMed: 7914580] 
6. Corder EH, Saunders AM, Risch NJ, et al. Protective effect of apolipoprotein E type 2 allele for late onset Alzheimer disease. Nat Genet. 1994; 7(2):180-184. [PubMed: 7920638]

7. Smith AD, Johnston C, Sim E, et al. Protective effect of apo epsilon 2 in Alzheimer'sdisease. Oxford Project to Investigate Memory and Ageing (OPTIMA). Lancet. 1994; 344(8920):473-474.

[PubMed: 7914581]

8. Talbot C, Lendon C, Craddock N, et al. Protection against Alzheimer's disease with apoE epsilon 2. Lancet. 1994; 343(8910):1432-1433. [PubMed: 7910910]

9. West HL, Rebeck GW, Hyman BT. Frequency of the apolipoprotein E epsilon 2 allele is diminished in sporadic Alzheimer disease. Neurosci Lett. 1994; 175(1-2):46-48. [PubMed: 7970208]

10. Caselli RJ, Walker D, Sue L, et al. Amyloid load in nondemented brains correlates with APOE e4. Neurosci Lett. 2010; 473(3):168-171. [PubMed: 20153809]

11. Gomez-Isla T, West HL, Rebeck GW, et al. Clinical and pathological correlates of apolipoprotein E epsilon 4 in Alzheimer's disease. Ann Neurol. 1996; 39(1):62-70. [PubMed: 8572669]

12. Hyman BT, West HL, Rebeck GW, et al. Quantitative analysis of senile plaques in Alzheimer disease: observation of log-normal size distribution and molecular epidemiology of differences associated with apolipoprotein E genotype and trisomy 21 (Down syndrome). Proc Natl Acad Sci U S A. 1995; 92(8):3586-3590. [PubMed: 7724603]

13. McNamara MJ, Gomez-Isla T, Hyman BT. Apolipoprotein E genotype and deposits of Abeta40 and Abeta42 in Alzheimer disease. Arch Neurol. 1998; 55(7):1001-1004. [PubMed: 9678319]

14. Morris CM, Benjamin R, Leake A, et al. Effect of apolipoprotein E genotype on Alzheimer's disease neuropathology in a cohort of elderly Norwegians. Neurosci Lett. 1995; 201(1):45-47. [PubMed: 8830309]

15. Nagy Z, Esiri MM, Jobst KA, et al. The effects of additional pathology on the cognitive deficit in Alzheimer disease. J Neuropathol Exp Neurol. 1997; 56(2):165-170. [PubMed: 9034370]

16. Ohm TG, Scharnagl H, März W, Bohl J. Apolipoprotein E isoforms and the development of low and high Braak stages of Alzheimer's disease-related lesions. Acta Neuropathol (Berl). 1999; 98(3):273-280. [PubMed: 10483785]

17. Polvikoski T, Sulkava R, Haltia M, et al. Apolipoprotein E, dementia, and cortical deposition of beta-amyloid protein. N Engl J Med. 1995; 333(19):1242-1247. [PubMed: 7566000]

18. Schmechel DE, Saunders AM, Strittmatter WJ, et al. Increased amyloid beta-peptide deposition in cerebral cortex as a consequence of apolipoprotein E genotype in late-onset Alzheimer disease. Proc Natl Acad Sci U S A. 1993; 90(20):9649-9653. [PubMed: 8415756]

19. Tiraboschi P, Hansen LA, Masliah E, et al. Impact of APOE genotype on neuropathologic and neurochemical markers of Alzheimer disease. Neurology. 2004; 62(11):1977-1983. [PubMed: 15184600]

20. Yip AG, McKee AC, Green RC, et al. APOE, vascular pathology, and the AD brain. Neurology. 2005; 65(2):259-265. [PubMed: 16043796]

21. Berg L, McKeel DW, Miller JP, et al. Clinicopathologic studies in cognitively healthy aging and Alzheimer's disease: relation of histologic markers to dementia severity, age, sex, and apolipoprotein E genotype. Arch Neurol. 1998; 55(3):326-335. [PubMed: 9520006]

22. Chalmers K, Wilcock GK, Love S. APOE epsilon 4 influences the pathological phenotype of Alzheimer's disease by favouring cerebrovascular over parenchymal accumulation of A beta protein. Neuropathol Appl Neurobiol. 2003; 29(3):231-238. [PubMed: 12787320]

23. Greenberg SM, Rebeck GW, Vonsattel JP, et al. Apolipoprotein E epsilon 4 and cerebral hemorrhage associated with amyloid angiopathy. Ann Neurol. 1995; 38(2):254-259. [PubMed: 7654074]

24. Olichney JM, Hansen LA, Hofstetter CR, et al. Association between severe cerebral amyloid angiopathy and cerebrovascular lesions in Alzheimer disease is not a spurious one attributable to apolipoprotein E4. Arch Neurol. 2000; 57(6):869-874. [PubMed: 10867785]

25. Premkumar DR, Cohen DL, Hedera P, et al. Apolipoprotein E-epsilon4 alleles in cerebral amyloid angiopathy and cerebrovascular pathology associated with Alzheimer's disease. Am J Pathol. 1996; 148(6):2083-2095. [PubMed: 8669492] 
26. Rannikmäe K, Kalaria RN, Greenberg SM, et al. APOE associations with severe CAA-associated vasculopathic changes: collaborative meta-analysis. J Neurol Neurosurg Psychiatry. 2014; 85(3): 300-305. [PubMed: 24163429]

27. Barthel H, Gertz HJ, Dresel S, et al. Cerebral amyloid- $\beta$ PET with florbetaben (18F) in patients with Alzheimer's disease and healthy controls: a multicentre phase 2 diagnostic study. Lancet Neurol. 2011; 10(5):424-435. [PubMed: 21481640]

28. Drzezga A, Grimmer T, Henriksen G, et al. Effect of APOE genotype on amyloid plaque load and gray matter volume in Alzheimer disease. Neurology. 2009; 72(17):1487-1494. [PubMed: 19339712]

29. Johnson KA, Sperling RA, Gidicsin CM, et al. Florbetapir (F18-AV-45) PET to assess amyloid burden in Alzheimer's disease dementia, mild cognitive impairment, and normal aging. Alzheimers Dement J Alzheimers Assoc. 2013; 9(5 Suppl):S72-S83.

30. Morris JC, Roe CM, Xiong C, et al. APOE predicts amyloid-beta but not tau Alzheimer pathology in cognitively normal aging. Ann Neurol. 2010; 67(1):122-131. [PubMed: 20186853]

31. Reiman EM, Chen K, Liu X, et al. Fibrillar amyloid-beta burden in cognitively normal people at 3 levels of genetic risk for Alzheimer's disease. Proc Natl Acad Sci U S A. 2009; 106(16):68206825. [PubMed: 19346482]

32. Bu G. Apolipoprotein E and its receptors in Alzheimer's disease: pathways, pathogenesis and therapy. Nat Rev Neurosci. 2009; 10(5):333-344. [PubMed: 19339974]

33. Kim J, Basak JM, Holtzman DM. The role of apolipoprotein E in Alzheimer's disease. Neuron. 2009; 63(3):287-303. [PubMed: 19679070]

34. Nagy Z, Esiri MM, Jobst KA, et al. Influence of the apolipoprotein E genotype on amyloid deposition and neurofibrillary tangle formation in Alzheimer's disease. Neuroscience. 1995; 69(3): 757-761. [PubMed: 8596645]

35. Bennett DA, Schneider JA, Wilson RS, et al. Amyloid mediates the association of apolipoprotein E e4 allele to cognitive function in older people. J Neurol Neurosurg Psychiatry. 2005; 76(9):11941199. [PubMed: 16107349]

36. Mungas D, Tractenberg R, Schneider JA, et al. A 2-process model for neuropathology of Alzheimer's disease. Neurobiol Aging. 2014; 35(2):301-308. [PubMed: 24080173]

37. Berlau DJ, Corrada MM, Robinson JL, et al. Neocortical $\beta$-amyloid area is associated with dementia and APOE in the oldest-old. Alzheimers Dement J Alzheimers Assoc. 2013; 9(6):699_ 705.

38. Lippa CF, Smith TW, Saunders AM, et al. Apolipoprotein E-epsilon 2 and Alzheimer's disease: genotype influences pathologic phenotype. Neurology. 1997; 48(2):515-519. [PubMed: 9040748]

39. Beekly DL, Ramos EM, Lee WW, et al. The National Alzheimer's Coordinating Center (NACC) database: the Uniform Data Set. Alzheimer Dis Assoc Disord. 2007; 21(3):249-258. [PubMed: 17804958]

40. Morris JC, Weintraub S, Chui HC, et al. The Uniform Data Set (UDS): clinical and cognitive variables and descriptive data from Alzheimer Disease Centers. Alzheimer Dis Assoc Disord. 2006; 20(4):210-216. [PubMed: 17132964]

41. Weintraub S, Salmon D, Mercaldo N, et al. The Alzheimer's Disease Centers' Uniform Data Set (UDS): the neuropsychologic test battery. Alzheimer Dis Assoc Disord. 2009; 23(2):91-101. [PubMed: 19474567]

42. Morris JC. The Clinical Dementia Rating (CDR): current version and scoring rules. Neurology. 1993; 43(11):2412-2414. [PubMed: 8232972]

43. Folstein MF, Folstein SE, McHugh PR. "Mini-mental state". A practical method for grading the cognitive state of patients for the clinician. J Psychiatr Res. 1975; 12(3):189-198. [PubMed: 1202204]

44. Braak H, Braak E. Neuropathological stageing of Alzheimer-related changes. Acta Neuropathol (Berl). 1991; 82(4):239-259. [PubMed: 1759558]

45. Braak H, Alafuzoff I, Arzberger T, et al. Staging of Alzheimer disease-associated neurofibrillary pathology using paraffin sections and immunocytochemistry. Acta Neuropathol (Berl). 2006; 112(4):389-404. [PubMed: 16906426] 
46. Mirra SS, Heyman A, McKeel D, et al. The Consortium to Establish a Registry for Alzheimer's Disease (CERAD). Part II. Standardization of the neuropathologic assessment of Alzheimer's disease. Neurology. 1991; 41(4):479-486. [PubMed: 2011243]

47. Thal DR, Rüb U, Orantes M, Braak H. Phases of A beta-deposition in the human brain and its relevance for the development of AD. Neurology. 2002; 58(12):1791-1800. [PubMed: 12084879]

48. Montine TJ, Phelps CH, Beach TG, et al. National Institute on Aging-Alzheimer's Association guidelines for the neuropathologic assessment of Alzheimer's disease: a practical approach. Acta Neuropathol (Berl). 2012; 123(1):1-11. [PubMed: 22101365]

49. Hyman BT, Phelps CH, Beach TG, et al. National Institute on Aging-Alzheimer's Association guidelines for the neuropathologic assessment of Alzheimer's disease. Alzheimers Dement $\mathbf{J}$ Alzheimers Assoc. 2012; 8(1):1-13.

50. Agresti, A.; Agresti, A. Categorical Data Analysis. Hoboken, NJ, USA: John Wiley \& Sons, Inc.; 2002. InternetAvailable from: http://doi.wiley.com/10.1002/0471249688 [cited 2013 May 30]

51. Yee TM. The VGAM package for categorical data analysis. J Stat Softw. 2010; 32(10):1-34.

52. Serrano-Pozo A, Qiang J, Monsell SE, et al. Examination of the clinicopathologic continuum of Alzheimer disease in the autopsy cohort of the National Alzheimer Coordinating Center. $\mathrm{J}$ Neuropathol Exp Neurol. 2013; 72

53. Imai K, Keele L, Tingley D. A general approach to causal mediation analysis. Psychol Methods. 2010; 15(4):309-334. [PubMed: 20954780]

54. Imai K, Yamamoto T. Identification and Sensitivity Analysis for Multiple Causal Mechanisms: Revisiting Evidence from Framing Experiments. Polit Anal. 2013; 21:141-171.

55. Tingley D, Yamamoto T, Hirose K, et al. mediation: R package for causal mediation analysis. J Stat Softw. 2014; 59(5):1-38.

56. Brecht WJ, Harris FM, Chang S, et al. Neuron-specific apolipoprotein e4 proteolysis is associated with increased tau phosphorylation in brains of transgenic mice. J Neurosci Off J Soc Neurosci. 2004; 24(10):2527-2534.

57. Fleming LM, Weisgraber KH, Strittmatter WJ, et al. Differential binding of apolipoprotein E isoforms to tau and other cytoskeletal proteins. Exp Neurol. 1996; 138(2):252-260. [PubMed: 8620924]

58. Huang DY, Weisgraber KH, Goedert M, et al. ApoE3 binding to tau tandem repeat I is abolished by tau serine262 phosphorylation. Neurosci Lett. 1995; 192(3):209-212. [PubMed: 7566652]

59. Huang Y, Liu XQ, Wyss-Coray T, et al. Apolipoprotein E fragments present in Alzheimer's disease brains induce neurofibrillary tangle-like intracellular inclusions in neurons. Proc Natl Acad Sci U S A. 2001; 98(15):8838-8843. [PubMed: 11447277]

60. Strittmatter WJ, Saunders AM, Goedert M, et al. Isoform-specific interactions of apolipoprotein E with microtubule-associated protein tau: implications for Alzheimer disease. Proc Natl Acad Sci U S A. 1994; 91(23):11183-11186. [PubMed: 7972031]

61. Hudry E, Dashkoff J, Roe AD, et al. Gene transfer of human Apoe isoforms results in differential modulation of amyloid deposition and neurotoxicity in mouse brain. Sci Transl Med. 2013; 5(212):212ra161.

62. Pooler AM, Polydoro M, Wegmann SK, et al. Tau-amyloid interactions in the rTgTauEC model of early Alzheimer's disease suggest amyloid-induced disruption of axonal projections and exacerbated axonal pathology. J Comp Neurol. 2013; 521(18):4236-4248. [PubMed: 23839581]

63. Bennett DA, Schneider JA, Wilson RS, et al. Neurofibrillary tangles mediate the association of amyloid load with clinical Alzheimer disease and level of cognitive function. Arch Neurol. 2004; 61(3):378-384. [PubMed: 15023815]

64. Hashimoto T, Serrano-Pozo A, Hori Y, et al. Apolipoprotein E, especially apolipoprotein E4, increases the oligomerization of amyloid $\beta$ peptide. J Neurosci Off J Soc Neurosci. 2012; 32(43): 15181-15192.

65. Koffie RM, Hashimoto T, Tai HC, et al. Apolipoprotein E4 effects in Alzheimer's disease are mediated by synaptotoxic oligomeric amyloid- $\beta$. Brain J Neurol. 2012; 135(Pt 7):2155-2168.

66. Castellano JM, Kim J, Stewart FR, et al. Human apoE isoforms differentially regulate brain amyloid- $\beta$ peptide clearance. Sci Transl Med. 2011; 3(89):89ra57. 
67. Götz J, Chen F, van Dorpe J, Nitsch RM. Formation of neurofibrillary tangles in P3011 tau transgenic mice induced by Abeta 42 fibrils. Science. 2001; 293(5534):1491-1495. [PubMed: 11520988]

68. Lewis J, Dickson DW, Lin WL, et al. Enhanced neurofibrillary degeneration in transgenic mice expressing mutant tau and APP. Science. 2001; 293(5534):1487-1491. [PubMed: 11520987]

69. Greenberg SM, Vonsattel JP, Segal AZ, et al. Association of apolipoprotein E epsilon2 and vasculopathy in cerebral amyloid angiopathy. Neurology. 1998; 50(4):961-965. [PubMed: 9566379]

70. Bracco L, Piccini C, Baccini M, et al. Pattern and progression of cognitive decline in Alzheimer's disease: role of premorbid intelligence and ApoE genotype. Dement Geriatr Cogn Disord. 2007; 24(6):483-491. [PubMed: 18025782]

71. Dal Forno G, Rasmusson DX, Brandt J, et al. Apolipoprotein E genotype and rate of decline in probable Alzheimer's disease. Arch Neurol. 1996; 53(4):345-350. [PubMed: 8929157]

72. Growdon JH, Locascio JJ, Corkin S, et al. Apolipoprotein E genotype does not influence rates of cognitive decline in Alzheimer's disease. Neurology. 1996; 47(2):444-448. [PubMed: 8757018]

73. Kleiman T, Zdanys K, Black B, et al. Apolipoprotein E epsilon4 allele is unrelated to cognitive or functional decline in Alzheimer's disease: retrospective and prospective analysis. Dement Geriatr Cogn Disord. 2006; 22(1):73-82. [PubMed: 16699282]

74. Kurz A, Egensperger R, Haupt M, et al. Apolipoprotein E epsilon 4 allele, cognitive decline, and deterioration of everyday performance in Alzheimer's disease. Neurology. 1996; 47(2):440-443. [PubMed: 8757017]

75. Murphy GM Jr, Taylor J, Kraemer HC, et al. No association between apolipoprotein E epsilon 4 allele and rate of decline in Alzheimer's disease. Am J Psychiatry. 1997; 154(5):603-608. [PubMed: 9137113]

76. Norrman J, Brookes AJ, Yates C, St Clair D. Apolipoprotein E genotype and its effect on duration and severity of early and late onset Alzheimer's disease. Br J Psychiatry J Ment Sci. 1995; 167(4): 533-536.

77. Tschanz JT, Corcoran CD, Schwartz S, et al. Progression of cognitive, functional, and neuropsychiatric symptom domains in a population cohort with Alzheimer dementia: the Cache County Dementia Progression study. Am J Geriatr Psychiatry Off J Am Assoc Geriatr Psychiatry. 2011; 19(6):532-542.

78. Hoyt BD, Massman PJ, Schatschneider C, et al. Individual growth curve analysis of APOE epsilon 4-associated cognitive decline in Alzheimer disease. Arch Neurol. 2005; 62(3):454-459. [PubMed: 15767511]

79. Stern Y, Brandt J, Albert M, et al. The absence of an apolipoprotein epsilon4 allele is associated with a more aggressive form of Alzheimer's disease. Ann Neurol. 1997; 41(5):615-620. [PubMed: 9153523]

80. Van der Vlies AE, Koedam ELGE, Pijnenburg YAL, et al. Most rapid cognitive decline in APOE epsilon4 negative Alzheimer's disease with early onset. Psychol Med. 2009; 39(11):1907-1911. [PubMed: 19335933]

81. Bonner-Jackson A, Okonkwo O, Tremont G. Alzheimer's Disease Neuroimaging Initiative. Apolipoprotein E $\varepsilon 2$ and functional decline in amnestic mild cognitive impairment and Alzheimer disease. Am J Geriatr Psychiatry Off J Am Assoc Geriatr Psychiatry. 2012; 20(7):584-593.

82. Wilson RS, Bienias JL, Berry-Kravis E, et al. The apolipoprotein E epsilon 2 allele and decline in episodic memory. J Neurol Neurosurg Psychiatry. 2002; 73(6):672-677. [PubMed: 12438469]

83. Beach TG, Monsell SE, Phillips LE, Kukull W. Accuracy of the clinical diagnosis of Alzheimer disease at National Institute on Aging Alzheimer Disease Centers, 2005-2010. J Neuropathol Exp Neurol. 2012; 71(4):266-273. [PubMed: 22437338]

84. Serrano-Pozo A, Qian J, Monsell SE, et al. Mild to moderate Alzheimer dementia with insufficient neuropathological changes. Ann Neurol. 2014; 75(4):597-601. [PubMed: 24585367] 


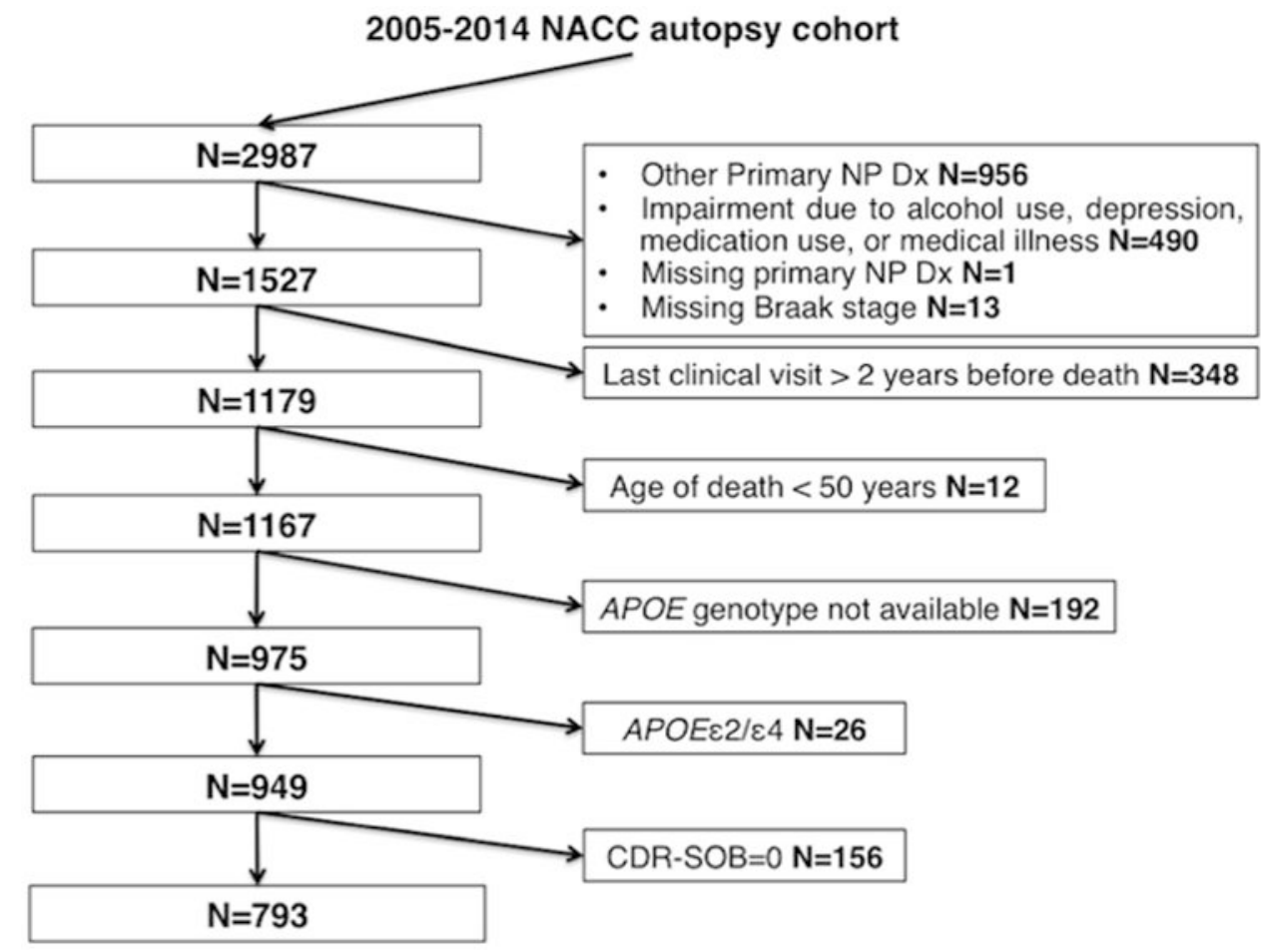

Figure 1.

Flow-chart of the selection process from March 2014 data freeze of the National Alzheimer's Coordinating Center (NACC) autopsy cohort. Other primary NP Dx: other primary neuropathological diagnoses refer to conditions other from Alzheimer disease and includes frontotemporal lobar degeneration, progressive supranuclear palsy, corticobasal degeneration, dementia with Lewy bodies, Parkinson disease, hypoxia, hemorrhage/ hematoma, necrosis, vascular dementia, hippocampal sclerosis, and prion-associated diseases. 

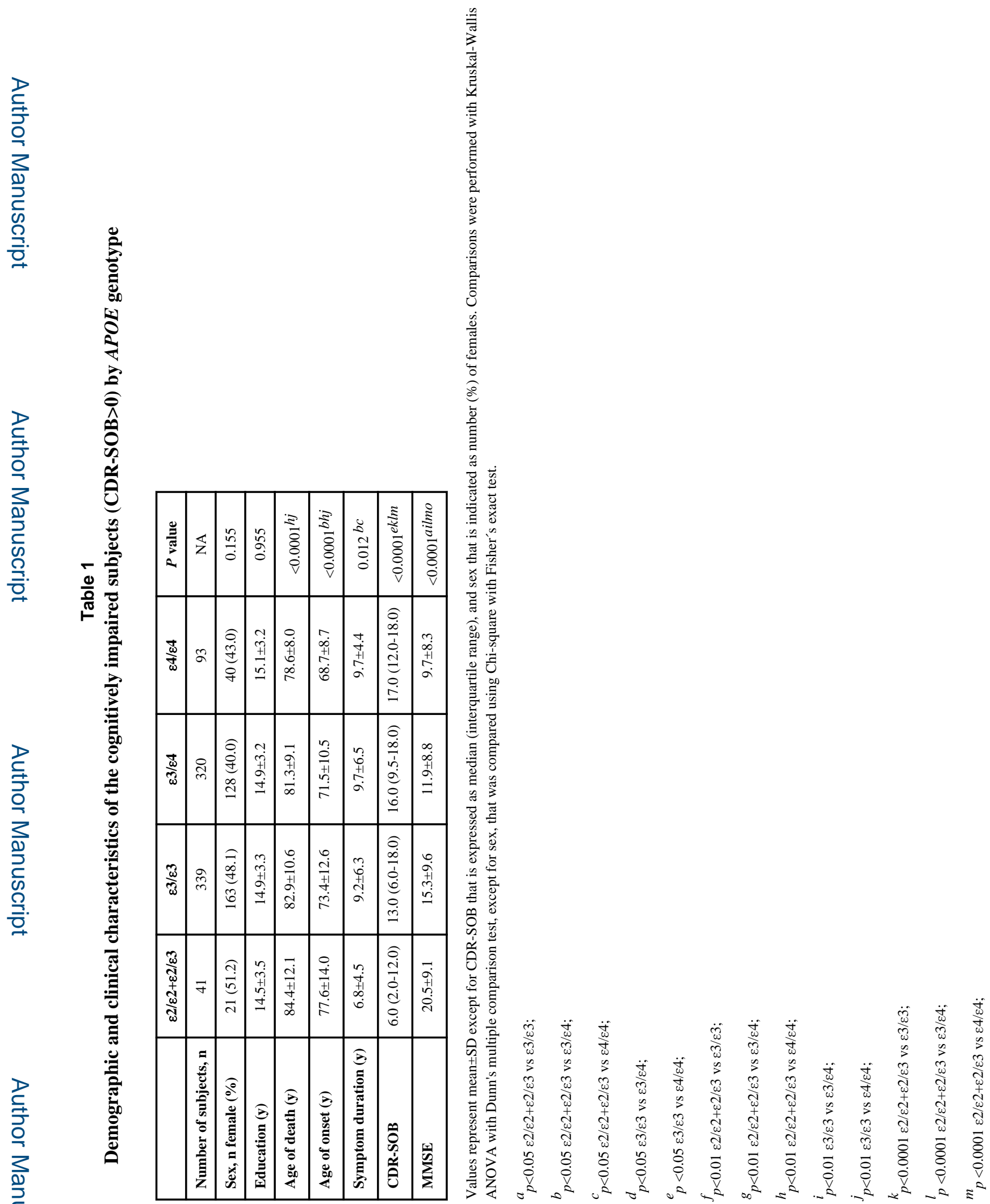

Ann Neurol. Author manuscript; available in PMC 2015 June 01. 


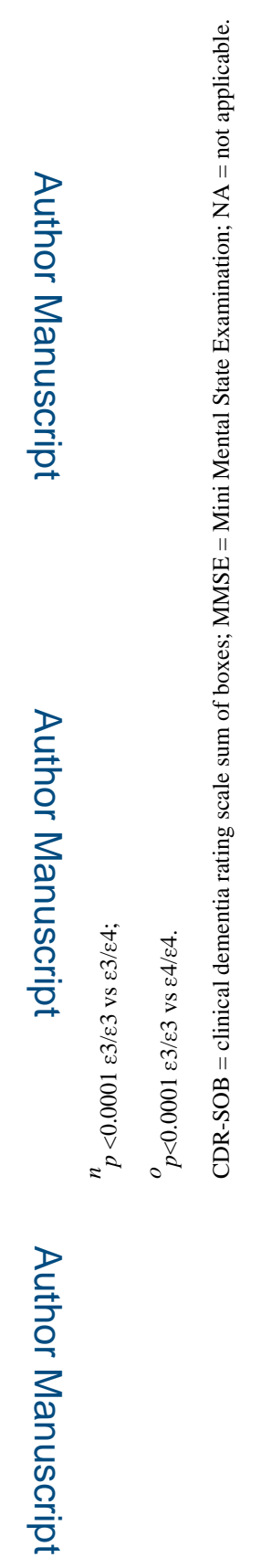

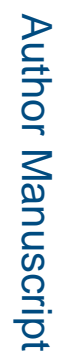

Ann Neurol. Author manuscript; available in PMC 2015 June 01. 


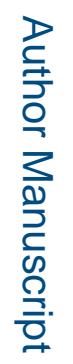

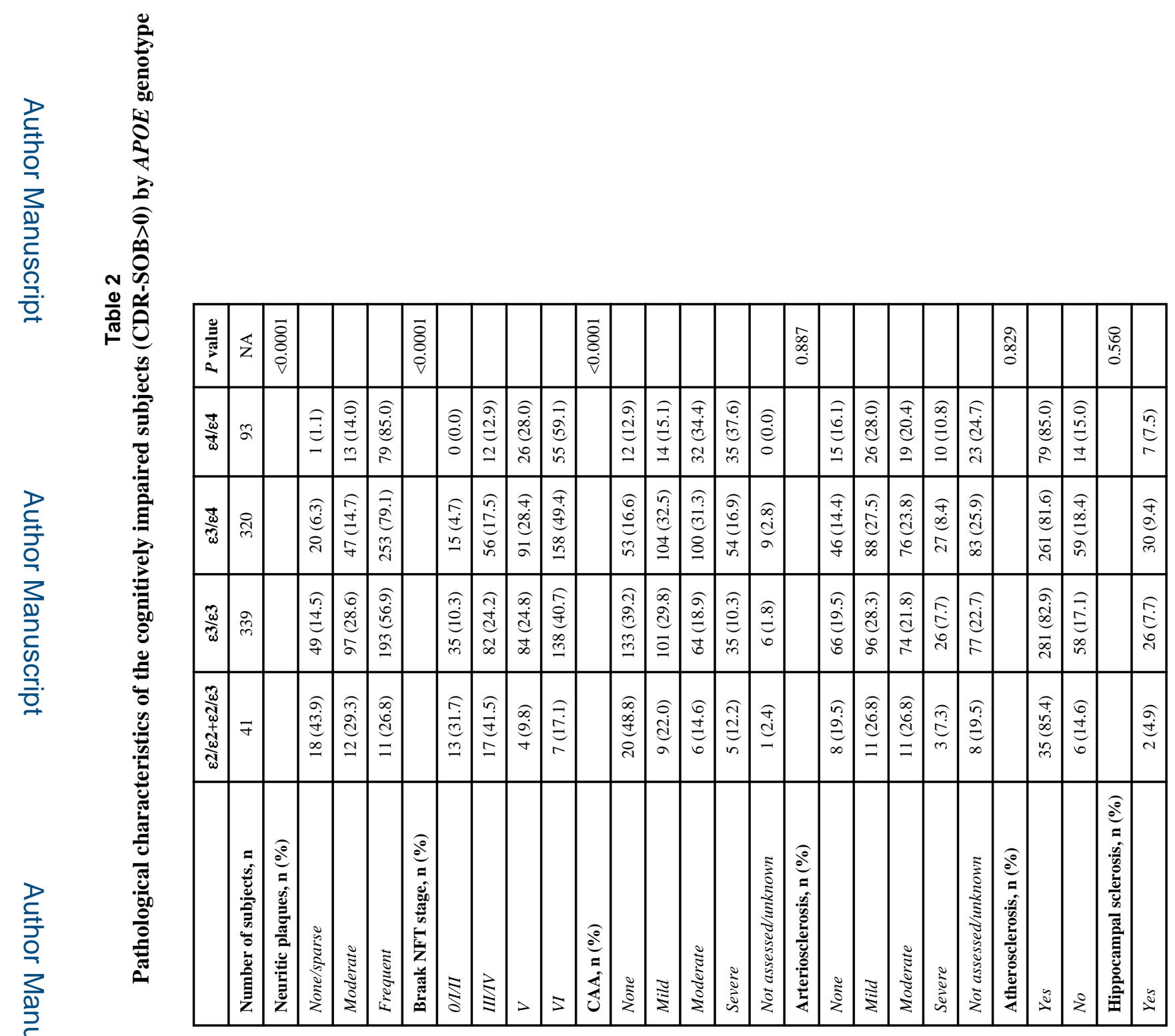

Ann Neurol. Author manuscript; available in PMC 2015 June 01. 


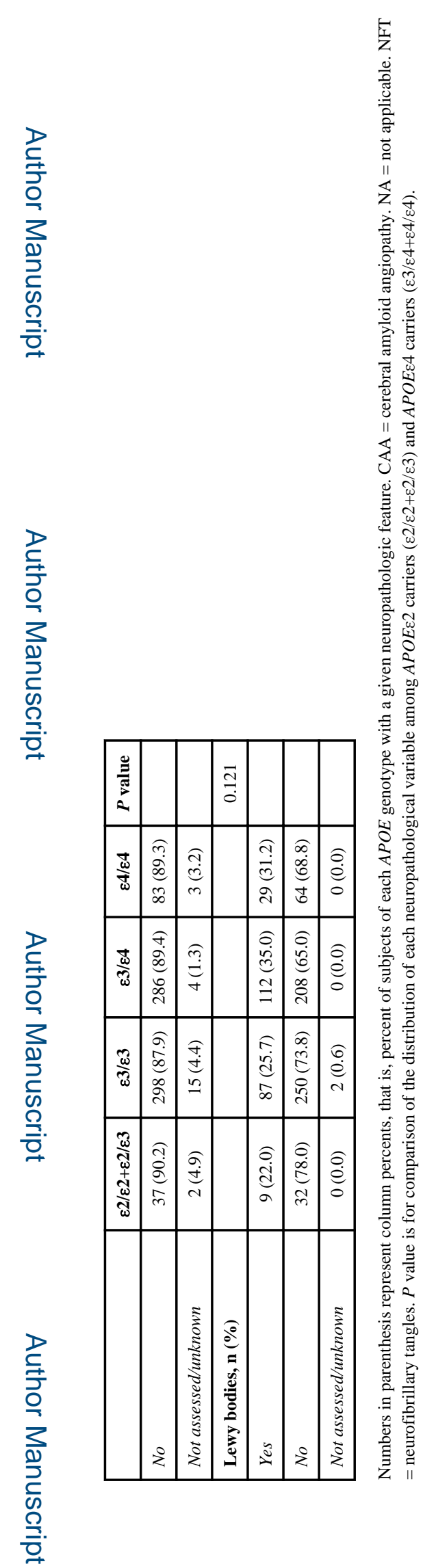

Ann Neurol. Author manuscript; available in PMC 2015 June 01. 


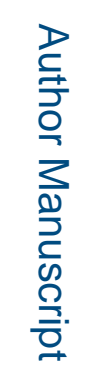

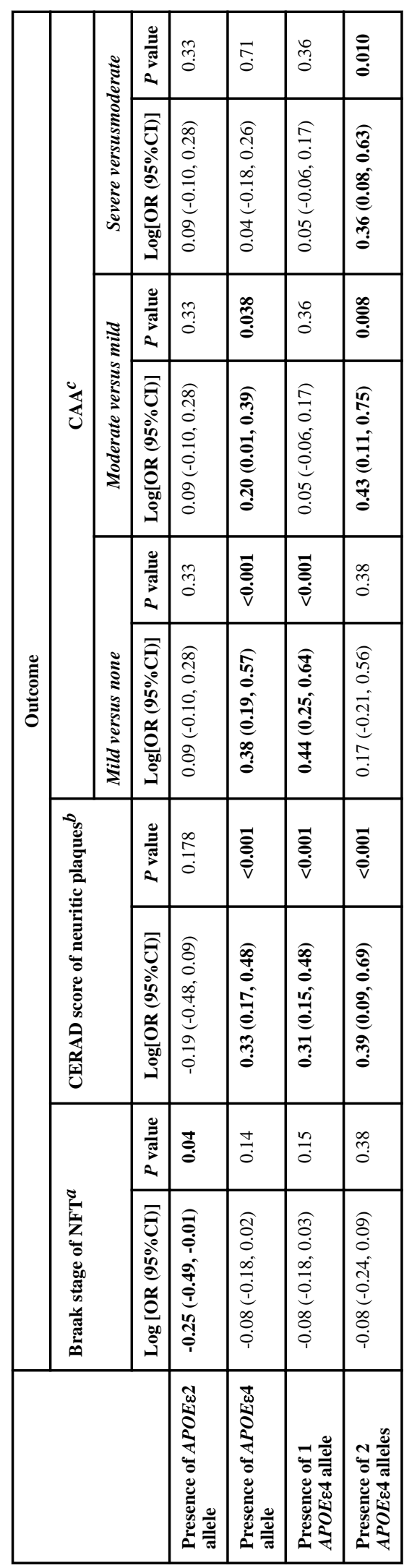

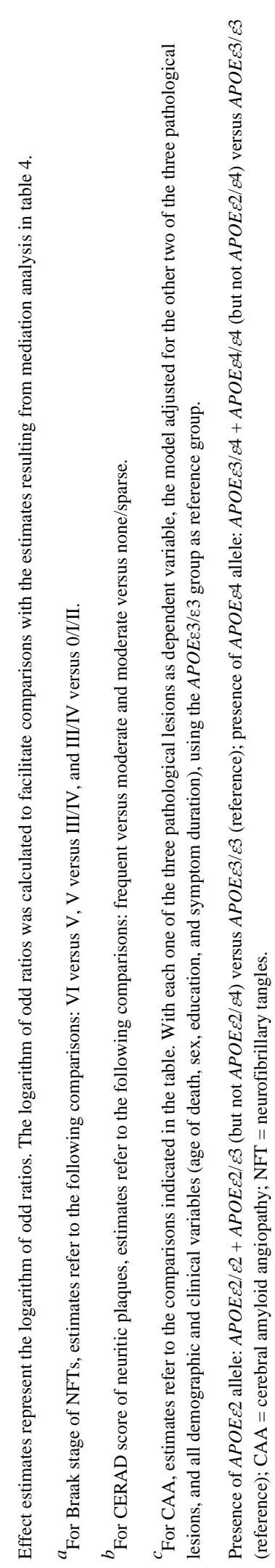

Ann Neurol. Author manuscript; available in PMC 2015 June 01. 
Table 4

Mediation analyses of the possible pathobiological pathways linking $A P O E$ alleles with AD pathological hallmarks

\begin{tabular}{|c|c|c|c|c|}
\hline \multirow{2}{*}{$\frac{\text { Outcome }}{\text { Neuritic plaques }}$} & \multicolumn{2}{|c|}{ Presence of $A P O E \varepsilon 2$ allele } & \multicolumn{2}{|c|}{ Presence of $A P O E \mathscr{E} 4$ allele } \\
\hline & Estimate (95\% CI) & $P$ value & Estimate (95\% CI) & $P$ value \\
\hline Total effect & $-0.85(-1.25,-0.46)$ & $<0.001$ & $0.33(0.18,0.48)$ & $<0.001$ \\
\hline Direct effect & $-0.42(-0.77,-0.09)$ & 0.02 & $0.23(0.11,0.35)$ & $<0.001$ \\
\hline \multicolumn{5}{|l|}{ Indirect effects: } \\
\hline through NFTs & $-0.42(-0.60,-0.25)$ & $<0.001$ & $0.10(0.02,0.17)$ & 0.008 \\
\hline through CAA & $-0.01(-0.04,0.03)$ & 0.56 & $-0.001(-0.03,0.02)$ & 0.96 \\
\hline Neurofibrillary tangles & Estimate (95\% CI) & $P$ value & Estimate (95\% CI) & $P$ value \\
\hline Total effect & $-1.33(-1.92,-0.71)$ & $<0.001$ & $0.30(0.06,0.54)$ & 0.02 \\
\hline Direct effect & $-0.60(-1.16,-0.06)$ & 0.03 & $0.06(-0.12,0.26)$ & 0.51 \\
\hline \multicolumn{5}{|l|}{ Indirect effects: } \\
\hline through plaques & $-0.72(-1.14,-0.31)$ & $<0.001$ & $0.19(0.04,0.35)$ & 0.006 \\
\hline through CAA & $-0.01(-0.09,0.06)$ & 0.69 & $0.05(0.01,0.10)$ & 0.01 \\
\hline Cerebral amyloid angiopathy & Estimate (95\% CI) & $P$ value & Estimate (95\% CI) & $P$ value \\
\hline Total effect & $-0.14(-0.53,0.26)$ & 0.41 & $0.53(0.36,0.69)$ & $<0.001$ \\
\hline Direct effect & $0.19(-0.18,0.54)$ & 0.31 & $0.45(0.30,0.61)$ & $<0.001$ \\
\hline \multicolumn{5}{|l|}{ Indirect effects: } \\
\hline through plaques & $-0.15(-0.29,-0.03)$ & 0.006 & $0.04(0.004,0.08)$ & $<0.001$ \\
\hline through NFTs & $-0.19(-0.33,-0.05)$ & $<0.001$ & $0.04(0.003,0.08)$ & 0.01 \\
\hline
\end{tabular}

Effect estimates represent coefficients from linear models. Cutoffs for mediators were selected based on our prior findings of pathological correlates of cognition in NACC autopsy cohort ${ }^{52}$, as follows: for neuritic plaques, none/sparse versus moderate/frequent; for Braak NFT stage, 0 to IV versus V/VI, and for CAA, none/mild versus moderate/severe. For the APOEE2 model, mediators include two of the three AD pathological hallmarks other than the one as dependent variable; additionally, the model is adjusted for age of death, gender, and education as confounders. $A P O E \varepsilon 4$ analyses are similar to $A P O E \varepsilon 2$, but additionally adjusted for symptom duration, presence of hippocampal sclerosis, and severity of arteriosclerosis (ischemic small vessel disease).

Presence of $A P O E \varepsilon 2$ allele: $A P O E \varepsilon 2 / \varepsilon 2+A P O E \varepsilon 2 / \varepsilon 3$ (but not $A P O E \varepsilon 2 / \varepsilon 4$ ) versus $A P O E \varepsilon 3 / \varepsilon 3$ (reference); presence of $A P O E \varepsilon 4$ allele: $A P O E \varepsilon 3 / \varepsilon 4+A P O E \varepsilon 4 / \varepsilon 4$ (but not $A P O E \varepsilon 2 / \varepsilon 4$ ) versus $A P O E \varepsilon 3 / \varepsilon 3$ (reference); CAA = cerebral amyloid angiopathy; NFT = neurofibrillary tangles. 
Table 5

Impact of $A P O E$ alleles on cognition (CDR-SOB and MMSE) and mediators of their impact

\begin{tabular}{|c|c|c|c|c|}
\hline & \multicolumn{4}{|c|}{ CDR-SOB } \\
\hline & \multicolumn{2}{|c|}{ Presence of $A P O E \& 2$ allele } & \multicolumn{2}{|c|}{ Presence of $A P O E \varepsilon 4$ allele } \\
\hline & Estimate $(95 \%$ CI $)$ & $P$ value & Estimate (95\% CI) & $P$ value \\
\hline Total effect & $-2.89(-4.77,-0.93)$ & 0.004 & $0.62(-0.17,1.35)$ & 0.10 \\
\hline Direct effect & $-0.76(-2.56,0.99)$ & 0.42 & $-0.29(-0.98,0.32)$ & 0.36 \\
\hline \multicolumn{5}{|l|}{ Indirect effects: } \\
\hline through neuritic plaques & $-0.82(-1.56,-0.09)$ & 0.004 & $0.24(0.08,0.41)$ & $<0.001$ \\
\hline through NFTs & $-1.65(-2.50,-0.79)$ & $<0.001$ & $0.34(0.12,0.57)$ & $<0.001$ \\
\hline through CAA & NA & NA & $0.16(0.00,0.33)$ & 0.05 \\
\hline \multirow[t]{4}{*}{ through age of onset } & $-0.32(-0.88,0.25)$ & 0.24 & $0.19(0.03,0.35)$ & 0.01 \\
\hline & \multicolumn{4}{|c|}{ MMSE } \\
\hline & \multicolumn{2}{|c|}{ Presence of $A P O E \varepsilon 2$ allele } & \multicolumn{2}{|c|}{ Presence of $A P O E \varepsilon 4$ allele } \\
\hline & Estimate (95\% CI) & $P$ value & Estimate $(95 \%$ CI $)$ & $P$ value \\
\hline Total effect & $3.49(-0.13,6.47)$ & 0.07 & $-3.10(-4.35,-1.80)$ & 0.002 \\
\hline Direct effect & $-0.33(-3.15,2.60)$ & 0.83 & $-0.98(-2.13,0.18)$ & 0.13 \\
\hline \multicolumn{5}{|l|}{ Indirect effects: } \\
\hline through neuritic plaques & $1.17(0.11,2.24)$ & 0.01 & $-0.33(-0.59,-0.07)$ & 0.002 \\
\hline through NFTs & $2.42(1.10,3.74)$ & $<0.001$ & $-0.66(-1.09,-0.22)$ & 0.004 \\
\hline through CAA & NA & NA & $-0.56(-0.93,-0.19)$ & $<0.001$ \\
\hline through age of onset & $0.33(-0.63,1.30)$ & 0.46 & $-0.62(-1.00,-0.24)$ & $<0.001$ \\
\hline
\end{tabular}

Effect estimates represent coefficients from linear models. For the APOE 2 model, mediators include two AD pathological hallmarks (neuritic plaques and NFTs) and age of onset, whereas confounders include gender, education, symptom duration, and CAA. We could not include CAA as a mediator for $A P O E \varepsilon 2$ due to the small sample size of this group. For the APOE\&4 model, mediators include the three AD pathological hallmarks (neuritic plaques, NFTs, and CAA) and age of onset, whereas confounders include gender, education, and symptom duration.

Presence of $A P O E \varepsilon 2$ allele: $A P O E \varepsilon 2 / \varepsilon 2+A P O E \varepsilon 2 / \varepsilon 3$ (but not $A P O E \varepsilon 2 / \varepsilon 4$ ) versus $A P O E \varepsilon 3 / \varepsilon 3$ (reference); presence of $A P O E \varepsilon 4$ allele: $A P O E \varepsilon 3 / \varepsilon 4+A P O E \varepsilon 4 / \varepsilon 4$ (but not $A P O E \varepsilon 2 / \varepsilon 4$ ) versus $A P O E \varepsilon 3 / \varepsilon 3$ (reference); CAA = cerebral amyloid angiopathy; $\mathrm{CDR}-\mathrm{SOB}=$ clinical dementia rating scale sum of boxes; MMSE = Mini Mental State Examination; NFT = neurofibrillary tangles. 